\title{
Optimum Load Sharing and Improving Stability in Distribution Network(LT)
}

\author{
V. Jayalakshmi, K. Sakthivel, S. Sherine
}

\begin{abstract}
This assignment paintings gives outline and reenactment of looking at, fault discovery of transformer, 3 level stack usage and misfortune assessment. undertaking indictors of a scattering transformer like load modern-day, voltage, transformer oil and incorporating temperatures and moistness. They need to take a gander at it consistently by using utilising this undertaking it is able to restrict working endeavors and enhance exactness, solidness, effectiveness in this mission, sensors are utilized to discover the primary parameters of equipment, for instance, voltage, present day(over voltage, underneath voltage, over contemporary) this detected data is despatched to microcontroller and this controller tests parameter limits which moreover ship to the $\mathrm{EB}$ control section[19],[20],[21]
\end{abstract}

Keywords : network,load,stability

\section{INTRODUCTION}

Coupled on top of things framework organize appropriation transformer is electrical tools which disperses capability to the low-voltage clients straightforwardly and its working situation is a vital piece of the venture of conveyance arrange. pastime of conveyance transformer underneath evaluated situation guarantees their long lifestyles. Be that as it can, their life is altogether lessened on the off chance that they are subjected to over-burdening situation, bringing about unexpected disappointments and lack of deliver to a considerable wide variety of clients on this manner influencing framework dependability. Over-burdening and ascend in oil and twisting temperature of transformer are the full-size reasons for disappointment in appropriation transformers. Irregularity in transformer is went with range in numerous parameters like winding temperature, oil temperature, surrounding temperature, stack gift, broke down gases in oil and oil level.The checking devices which can be by and through utilized for gazing transformer have a few troubles and inadequacies, as an instance, guide checking framework for the most element identifies a solitary parameter, for example, manipulate, present day, voltage and stage. even as in a few approaches it can become aware of multi-parameter. the right opportunity for purchasing the

\footnotetext{
Revised Manuscript Received on August 22, 2019.

Dr.V.Jayalakshmi, Department of EEE,Bharath Institute of Higher education and research, Tamilnadu, India. Email: Jayalakshmiv.eee@gmail.com

K.Sakthivel, Department of EEE,Bharath Institute of Higher education and research, Tamilnadu, India. Email: ksakthivelme@gmail.com

S.Sherine, Department of EEE,Bharath Institute of Higher education and
} research, Tamilnadu, India. Email: nssherine@gmail.com records or readings and running parameters is too long and checking out speed is not so quick enough. Discovery framework isn't always strong in view that negative enemy of sticking capability and coffee estimation exactness of the records. Opportune recognition information may not be sent to staring at focuses in time. fee of by using and with the aid of applied staring at framework is excessive. a few checking frameworks makes use of manipulate line bearer correspondence $(\%)$ to ship information however it has a few burdens of Frequency obstruction in framework and Noise trouble in arrange. [14],[ 16], [18]

\section{CASE STUDY}

\section{1: 250 KVA DT}

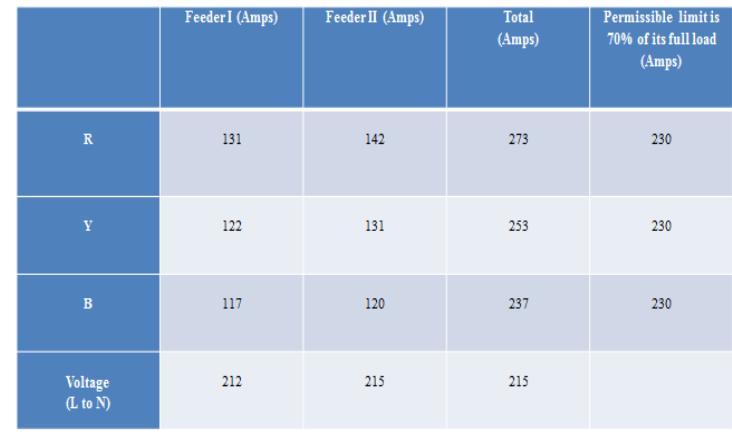

(40 Amps may be transfer to nearby DT to avoid overloading)

\section{2: 100 KVA DT}

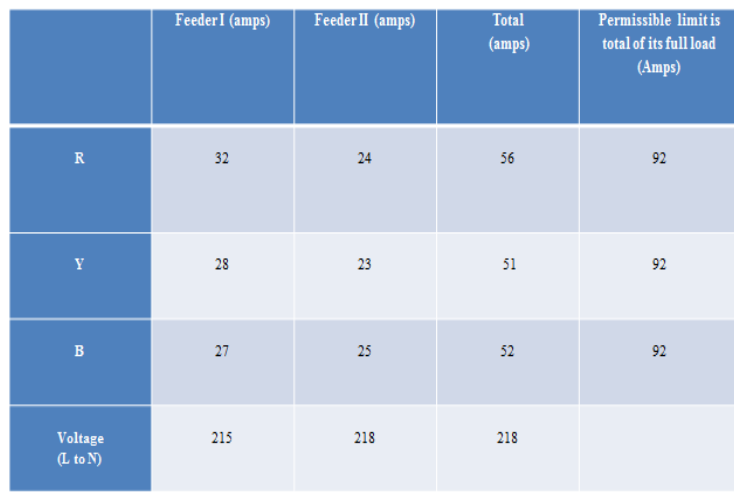

Fig.1.Ratings of 250KVA DT \&100KVA DT 
(40 Amps can be accommodate To nearby DT)

In 250KVA Distribution Transformer allowable load constrain is 70\% of its Full load limit i.e 230 Amps(Full Load 330 Amps) according to reality add up to utilization was 273 Amps which was $20 \%$ more than its ability which may prompts Overloading of DT. Because of over-burdening life time of DT may extensively diminished and furthermore prompts disappointment of DT Feeder link will likewise get visit flaws. [13], [15] ,[ 17]

To maintain a strategic distance from previously mentioned circumstance or events we propose a framework for stack sharing/adjusting from adjacent DT. According to contextual analysis, we can impart the heap to adjacent 100KVA DT from Overloaded DT. LT arrange steadiness can be enhanced by sharing burden among the DT's Performance of the DT's will be enhanced Power Interruption because of DT disappointment can be maintained a strategic distance from.

\section{SYSTEM DESIGN AND ARCHITECTURE}

Dispersion transformer consistent watching framework to distinguish every running parameter task, and send to the checking consciousness in time. It activates on line staring at of key operational parameters of dispersion transformers can supply treasured information approximately the electricity of transformers with a purpose to push the utilities to preferably make use of their transformers and preserve the benefit in task for a more prolonged duration. this could likewise assist distinguish issues earlier than any cataclysmic disappointment that may bring about a massive price reserve budget and extra noteworthy dependability. Dispersion Transformer over-burdening could be stayed faraway from and might likewise associate with adjacent conveyance transformer in view of stipulations and accessibility. Request guaging of extra DT likewise been assessed and misfortunes are figured.

\section{BLOCK DIAGRAM}

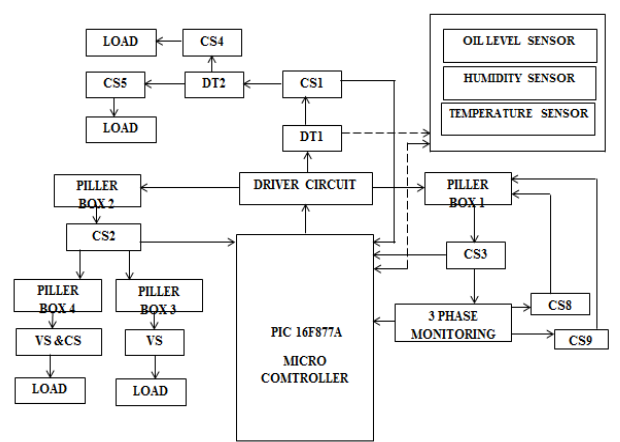

recognition in time. It prompts on line checking of key operational parameters of appropriation transformers can give valuable statistics approximately the stability of transformers for you to push the utilities to ideally make use of their transformers and preserve the benefit in mission for a more prolonged duration. [19],[20],[21]

this will likewise help understand troubles before any disastrous unhappiness which could bring about a vital fee funding finances and greater noteworthy unwavering quality.
Appropriation Transformer over-burdening will be kept far from and might likewise companion with near-through dissemination transformer in light of requirements and accessibility. Request figuring out of greater DT likewise been assessed and misfortunes are computed.

\section{NEED FORDRIVER CIRCUIT}

A motive force is an electrical circuit or other digital thing used to manipulate any other circuit or aspect, consisting of a high-strength transistor, liquid crystal show (liquid crystal display), and numerous others. they are usually used to adjust modern-day flowing thru a circuit or to manipulate different factors including other components, a few gadgets inside the circuit.

The time period is frequently used, for instance, for a specialised integrated circuit that controls high-energy switches in switched-mode power converters. typically the driver level(s) of a circuit calls for special traits to other circuit degrees. for instance in a transistor electricity amplifier circuit, typically the driving force circuit calls for cutting-edge advantage, often the capacity to discharge the subsequent transistor bases swiftly, and low output impedance to keep away from or decrease distortion. [8],[ 10] ,[12]

\section{CIRCUIT DIAGRAM}

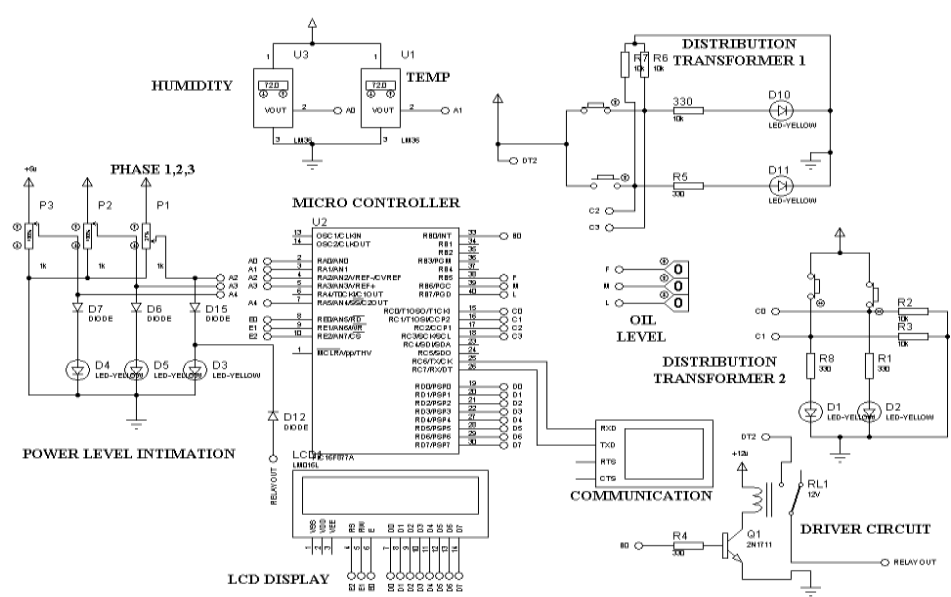




\section{V.SIMULATION DIAGRAM}

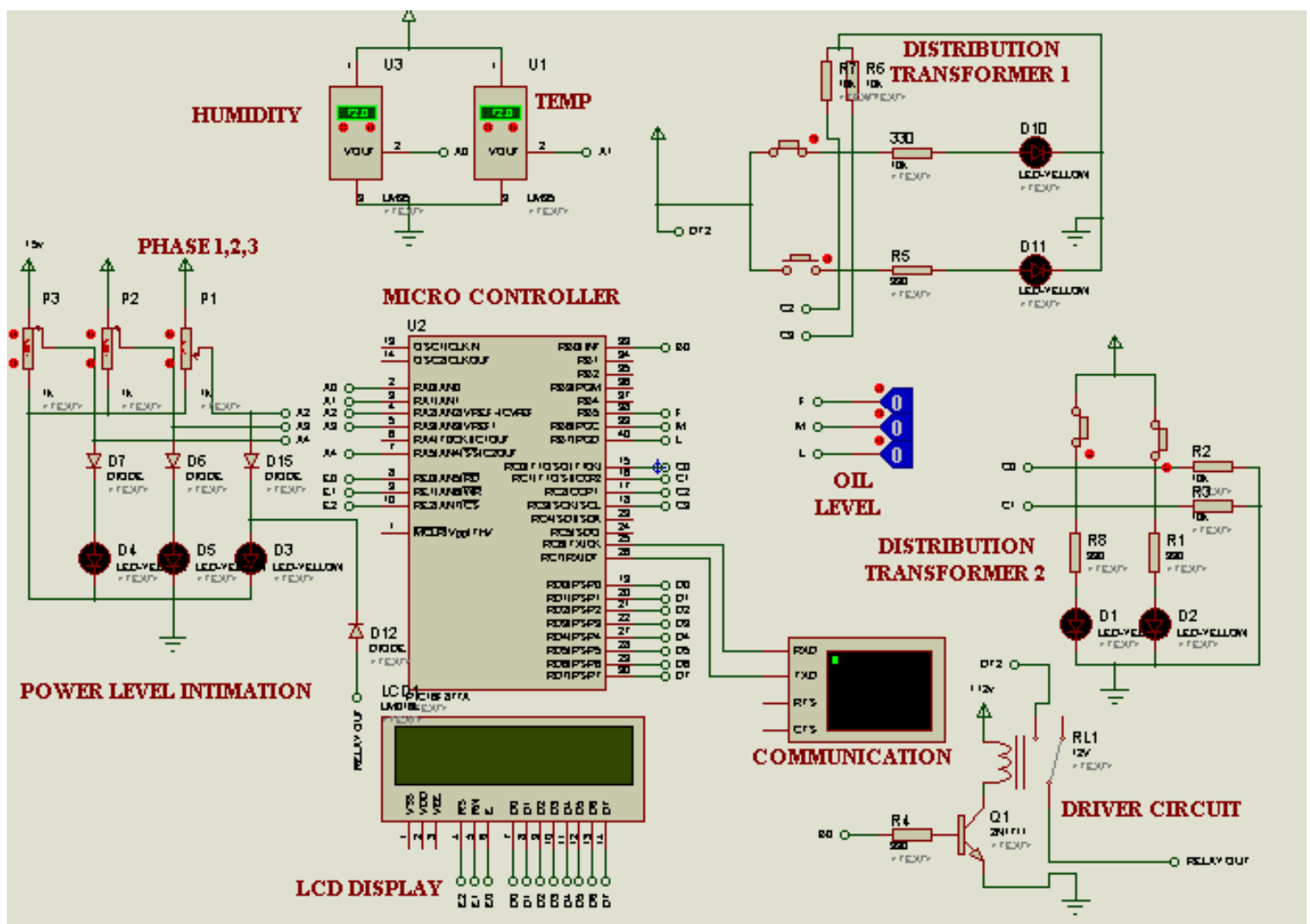

Fig.4.Simulation Diagram of proposed system

\section{SIMULATION RESULT}

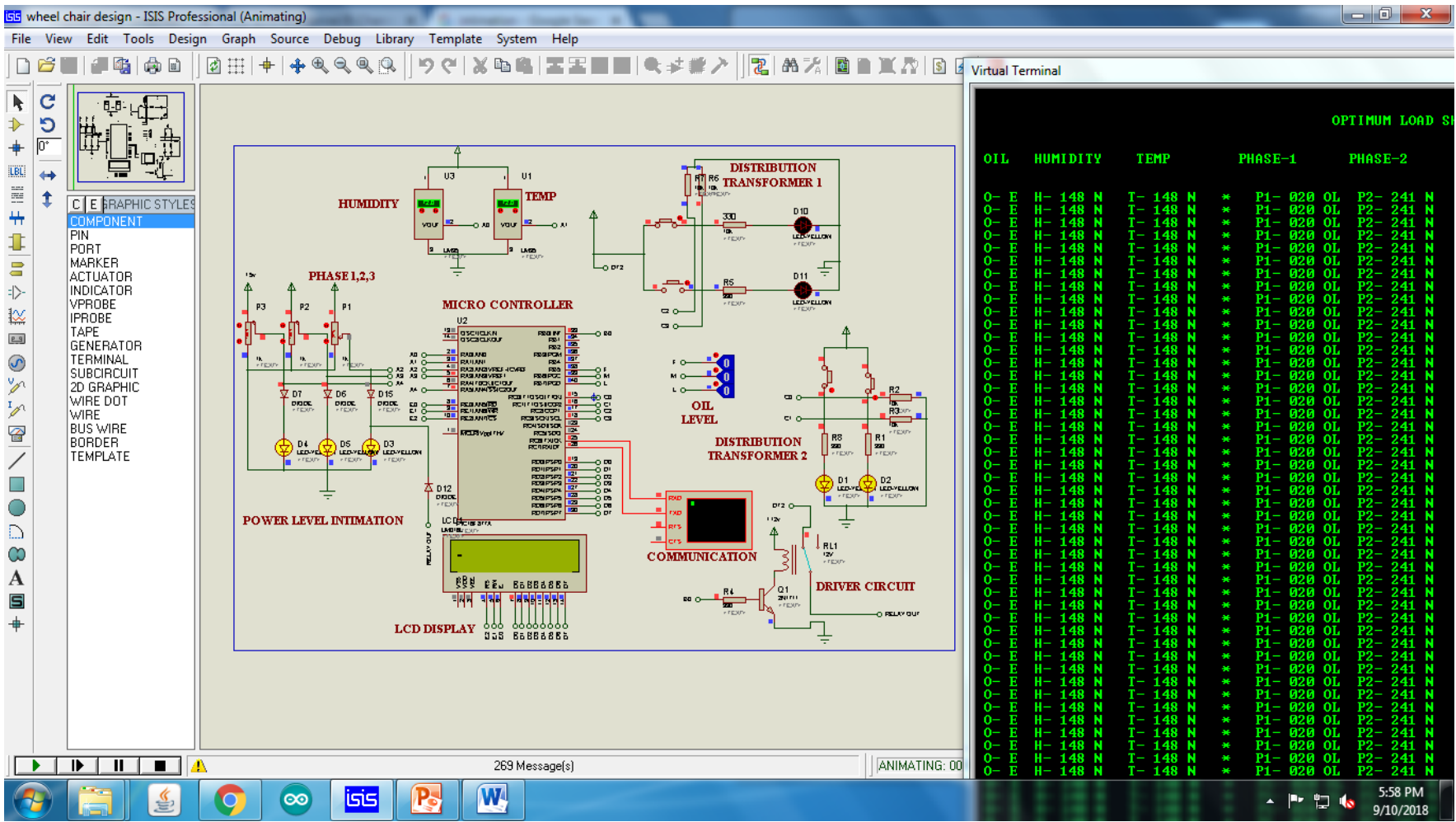

Fig.5.Simulation Result of proposed system

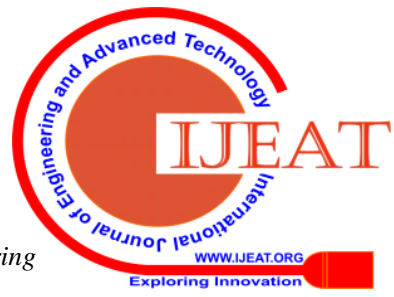




\section{VIRTUAL TERMINAL}

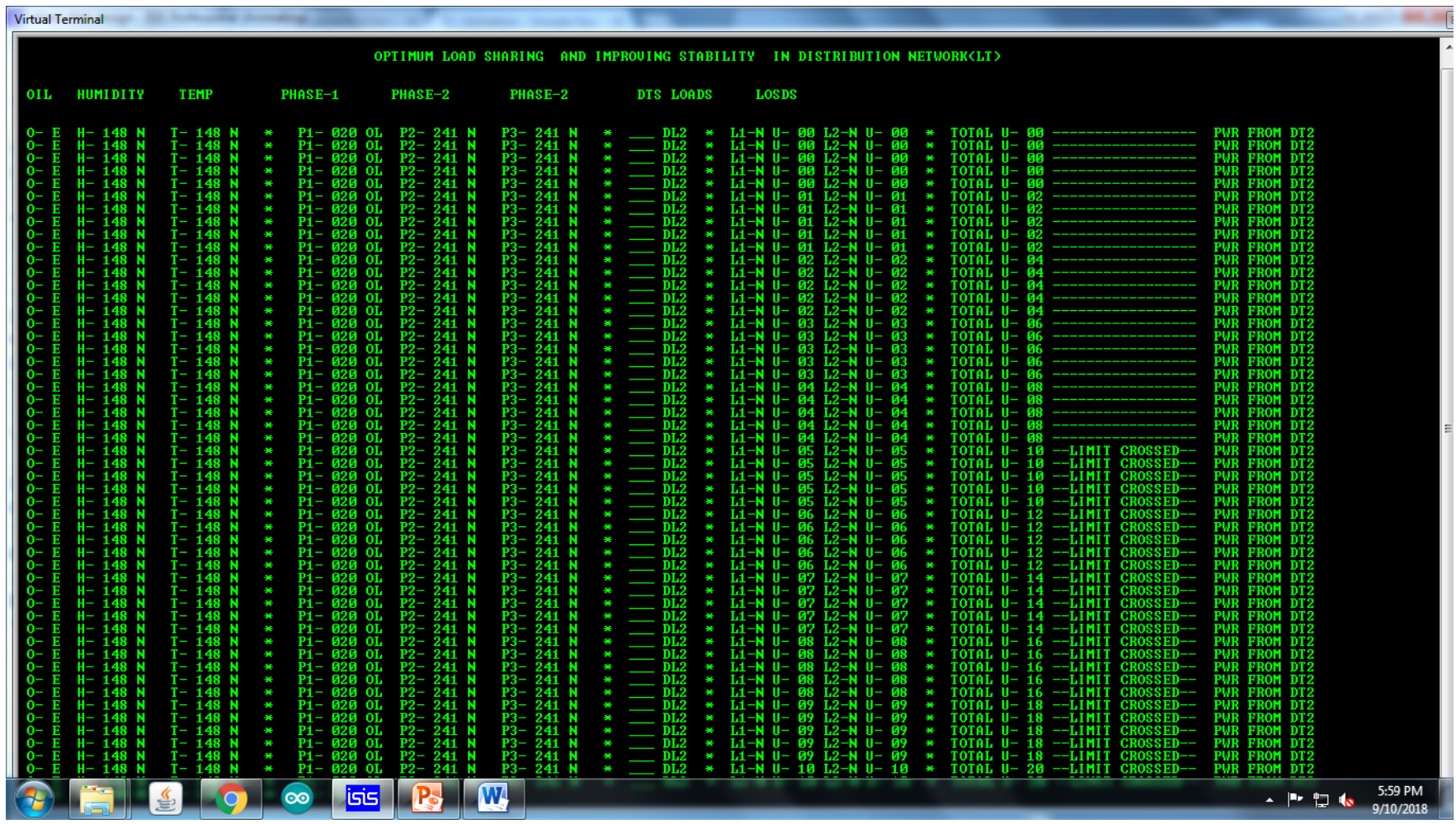

\section{Fig 6:SiMULATION RESULT OF PROPOSED SYSTEM}

\section{CONCLUSION}

With the utilization of sensors connected to this system, enables an efficient load sharing technique. Also the distributionis stabilized by this system. The overloading of the transformer is eliminated in this system by utilizing the above explained techniques. [13], [15] ,[17]

The utilization of the microcontroller with digital indicators provides the feasibility for people to easily analyse the physical parameters. [14],[16], [18]

\section{REFERENCES}

[1] Sharma, R.K., Irusapparajan, G. \& Periyaazhagar, D. 2019, "Three-phase symmetric cascading Z-source seven levels multilevel inverter excited by multi carrier sinusoidal pulse width modulation scheme", International Journal of Innovative Technology and Exploring Engineering, vol. 8, no. 10, pp. 4269-4274.

[2] Velavan, R., Bharanidharan, S. \& Sheeba, B. 2019, "EMF pollution Causes, effects and protection", International Journal of Innovative Technology and Exploring Engineering, vol. 8, no. 9 Special Issue 3, pp. 1166-1168.

[3] Saravana, S., Balaji, S., Arulselvi, S. \& John Paul Praveen, A. 2019, "Reliable power quality monitoring and protection system", International Journal of Innovative Technology and Exploring Engineering, vol. 8, no. 9 Special Issue 3, pp. 644-645.

[4] Tamil Selvan, S. \& Sundararajan, M. 2019, "Performance Parameters of 3 Value 8t Cntfet Based Sram Cell Design Using H-Spice", International Journal of Recent Technology and Engineering, vol. 8, no. 2 Special issue 5, pp. 22-27.

[5] Jac Fredo, A.R., Abilash, R.S., Femi, R., Mythili, A. \& Kumar, C.S 2019, "Classification of damages in composite images using Zernike moments and support vector machines", Composites Part B: Engineering, vol. 168 , pp. 77-86.

[6] Kathiravan, P. \& Govindaraju, C. 2019, "Design and evaluation of ultra gain isolated DC-DC converter for photovoltaic system", International Journal of Engineering and Advanced Technology, vol. 8, no. 5, pp. 2646-2651.
[7] Kripa, N., Vasuki, R. \& Kishore Kanna, R. 2019, "Realtime neural interface controlled au-pair BIMA bot", International Journal of Recent Technology and Engineering, vol. 8, no. 1, pp. 992-994.

[8] Mohanraj, Meenaa Kumari, M., Philomina, S. \& Jasmin, M. 2019, "In-situ humidity measurement of hydrogen fuel cell car using MEMS sensor", International Journal of Recent Technology and Engineering, vol. 8, no. 1, pp. 41-43.

[9] Velmurugan, T. \& Prakash, S. 2019, "Artificial intelligent based distribution automation of swift fault detection isolation and power restoration for HT network", International Journal of Innovative Technology and Exploring Engineering, vol. 8, no. 6, pp. 1-6.

[10] Dwarakesh, K. \& Prem Kumar, G. 2019, "Five-level inverter based sequential boost system using fuzzy logic controller", International Journal of Innovative Technology and Exploring Engineering, vol. 8, no. 6, pp. 12-19.

[11] Anne Gifta, A. \& Hemavathi, G. 2019, "Analysis of grid tied solar PV system using ANFIS Algorithm", International Journal of Innovative Technology and Exploring Engineering, vol. 8, no. 6, pp. 312-316.

[12] Jayavel, R., Rangaswamy, T.R. \& Prakash, S. 2019, "Efficient grid management system with renewable and conventional power sources", International Journal of Innovative Technology and Exploring Engineering, vol. 8, no. 6, pp. 287-289.

[13] Hemavathi, G. \& Maheshwaran, S. 2019, "Proportional resonant controlled high gain step-up converter system with improved response", International Journal of Innovative Technology and Exploring Engineering, vol. 8, no. 6, pp. 317-323.

[14] Periyaazhagar, D. \& Irusapparajan, G. 2019, "Design and completion of asymmetric single phase 27 level cascaded mli for various pwm scheme", International Journal of Innovative Technology and Exploring Engineering, vol. 8, no. 6, pp. 792-797.

[15] Mahalakshmi, V. \& Vijayaragavan, S.P. 2019, "PV based power electronic converters for high voltage DC applications", International Journal of Recent Technology and Engineering, vol. 7, no. 6, pp. 670-674.

[16] Irusapparajan, G., Periyaazhagar, D., Prabaharan, N. \& Rini Ann Jerin, A 2019, "Experimental verification of trinary DC source cascaded h-bridge multilevel inverter using unipolar pulse width modulation", Automatika, vol. 60 , no. 1 , pp. 19-27.

[17] Sangeetha, G., Sherine, S., Arputharaju, K. \& Prakash, S. 2019, "On Line Monitoring of Higher Rated Alternator using Automated Generator Capability Curve Administer", Proceedings of the IEEE International Conference on \&amp;quot;Recent Trends in Electrical, Control and Communication\&amp;quot; RTECC 2018, pp. 176. 
[18] Bycil, V.J. \& Wiselin, M.C.J. 2019, "Modeling and analysis of vibration energy harvesting system using piezo stack", International Journal of Mechanical and Production Engineering Research and Development, vol. 9, no. Special Issue 1, pp. 523-533.

[19] Sripada, A., Warrier, A., Kapoor, A., Gaur, H. \& Hemalatha, B. 2018, "Dynamic lateral balance of humanoid robots on unstable surfaces", International Conference on Electrical, Electronics, Communication Computer Technologies and Optimization Techniques, ICEECCOT 2017, pp. 539.

[20] Srinivasan, S., Thirumalaivasan, K. \& Sivakumaran, T.S. 2018, "Performance evaluation of double-output luo converters", Journal of Advanced Research in Dynamical and Control Systems, vol. 10, no. 10 Special Issue, pp. 870-878.

[21] Karthikayen, A. \& Selvakumar Raja, S. 2018, "A skellam distribution inspired trust factor-based selfish node detection technique in MANETs", Journal of Advanced Research in Dynamical and Control Systems, vol. 10, no. 13 , pp. $940-949$.

\section{AUTHORS PROFILE}

Dr.V.Jayalakshmi*, Associate Professor Department of EEE,Bharath Institute of Higher education and research, Tamilnadu, India.

K.Sakthivel Assistant Professor Department of EEE,Bharath Institute of Higher education and research, Tamilnadu, India.

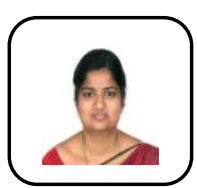

S.Sherine, Assistant Professor Department of EEE,Bharath Institute of Higher education and research, Tamilnadu, India 